\title{
EFFECTIVE LEADERSHIP IN ONLINE SMALL BUSINESSES: AN EXPLORATORY CASE STUDY
}

\author{
Mandy Smith \\ University of Phoenix, Phoenix, USA \\ Email: mandyffasw@yahoo.com
}

Received: 6 December 2020. Revision received: 16 December 2020. Accepted: 21 December 2020

\begin{abstract}
The exploratory case study, with a positive deviance approach, was used to address the problem that online small business leaders lack effective leadership skills and actions. Generally, online small business leaders face challenges separate and unique from traditional ground business leaders and different than big e-commerce business leaders who are turning ground businesses to online global businesses. Specifically, online small business leaders lack effective leadership skills and actions to address the unique challenges of online small businesses, resulting in a $90 \%$ first-year failure rate. Ten online small business leaders answered interview questions to explore best practices and processes. Data analysis revealed six themes of online small business leadership qualities but not particular leadership qualities practiced by online small business leaders. The major six qualities of the online small business leaders in this study consisted of having a passion and intrinsic motivation for their work, having a heightened awareness of time and time management, maintaining old fashioned face-to-face interactions, historically having someone of positive influence in their lives, being adaptable to change, and having high problem-solving and decisionmaking skills. Based on these new findings, more exploration of how these online small business leadership qualities could contribute to higher success rates is recommended.
\end{abstract}

KEYWORDS: leadership styles, leadership practices, online leaders, online businesses, exploratory case study

JEL CLASSIFICATION: D01, L26, L81

Reference: Smith, M. (2020). Effective Leadership in Online Small Businesses: an Exploratory Case Study. International Journal of Entrepreneurial Knowledge, 8(2), 27-41. doi: 10.37335/ijek.v8i2.117

\subsection{INTRODUCTION}

Michael Aldrich is credited with the inventing of online shopping via television, computer, and phone line connections in 1979, which led to an increased demand for online small business goods and services (Cohen-Almagor, 2011; Stern, Friedman, \& Friedman, 2017). The convenience of online small businesses quickly increased with the additional popularity and growth of the Internet in the 1980s and 1990s and lifted restrictions on commercial use of the Internet in 1991 (Cohen-Almagor, 2011; Stern et al., 2017). Big Internet businesses and retailers Amazon, eBay, and Yahoo all launched in 1995, followed by PayPal in 1998, which contributed to the closure of many retail ground businesses due to the popularity of online business and increased e-commerce (Stern et al., 2017). The popularity of online e-commerce added more shopping freedom, control, fun, and use of comments, reviews, and instant feedback between consumer and organizations (Dey, D’Souza, \& D'Souza, 2015; Wolfinbarger \& Gilly, 2001). Only 20 years ago, online businesses in its current form did not exist; however, today, online businesses account for 10\% of all business transactions, making it a $\$ 300$ billion industry (Friedman, 2014).

Although online small businesses have numerous benefits and rewards relative to brick-and-mortar companies (Mackinnon \& Pinette, 2016), the effective leadership qualities have not been thoroughly explored from the perspective of the successful online small business leaders (Cope \& Waddell, 2001). To gain a clearer perspective of the effectiveness of online small business leaders or their overall success, this study explored any ideal practices, decisions, optimal solutions of leadership, and views of future business growth, prosperity, and success from these leaders. The study focused only on online small businesses of ecommerce and their online small business leaders' personal practices and experiences 


\section{INTERNATIONAL JOURNAL OF ENTREPRENEURIAL KNOWLEDGE}

Issue 2, volume 8, ISSN 2336-2960 (Online)

www.ijek.org

reflected in effective leadership qualities. The participants in the study were online small business leaders who have continued to thrive in ecommerce despite the $90 \%$ failure rate within the first year of start-up (Bureau of Labor Statistics, 2015; United States Small Business Administration, 2019).

Vastly more online small businesses fail compared with their traditional brick-and-mortar counterparts (Lowell, 2016; Lupasc \& Gheorghe, 2016). Online small business leaders' unique challenges require effective decision making in various areas, such as technical problems, customer technological access, fewer face-to-face interactions for human connection, privacy and security concerns, limitations in marketing, lesser consumer product senses, theft of ideas, varied copyright laws, a larger global audience with high exposure issues, a hyperactive 24-hour environment, and highly integrated and specific social networks (Joseph, 2017; Verma, Sharma, \& Sheth, 2016). Identifying and using the most effective leadership qualities, actions, and processes in online small businesses, given the unique challenges previously listed, may result in better problem solving, decision-making, and troubleshooting for higher success rates and continued profits for online small businesses (Silzer, Church, Rotolo, \& Scott, 2016).

The general problem is that online small business leaders face challenges separate and unique from traditional ground business leaders and different than big ecommerce business leaders who are turning ground businesses to online global businesses (Lowell, 2016; Lupasc \& Gheorghe, 2016). The specific problem is that online small business leaders lack effective leadership qualities, skills, and actions to address the unique challenges of online small businesses, resulting in a 90\% first-year failure rate (Bureau of Labor Statistics, 2015; Raghupathi \& Fogel, 2015). A newer alternative mode of ecommerce has become increasingly popular, yet the effective leadership procedures being implemented to improve online small business opportunities have not been fully studied, particularly, the processes directly relayed from online small business leaders (Korzynski, 2013).

\subsection{THEORETICAL BASES}

Currently, research content regarding effective qualities of leadership styles in relation to online small businesses has focused either on how a leadership style relates to online commerce or how leadership styles relate to small business. However, the current content does not focus on how effective leadership qualities directly relate to online small businesses, especially from the perspective of online small business leaders'. The existing research has focused on transformational leadership, normative leadership, and complexity styles as positive factors and influences in small businesses overall (Franco \& Matos, 2015; Gross, 2016; Ng \& Kee, 2018).

Up to the present, leadership has been analyzed using various approaches to determine and create different leadership qualities. Historically, leadership styles and behaviors have been analyzed based on the trait, skills, behavioral, situational, and psychodynamic approaches. These leadership theories include intrinsic and extrinsic characteristics of the leader, proactive to reactive actions, combinations of internal and external environmental factors, and dynamic variations of time, change, and behaviors. This study sought to uncover what combination of these leadership qualities online small business leaders use to be effective and successful in their organization (Gross, 2016; Ng \& Kee, 2018).

The majority of the conceptual framework literature related to effectively leadership styles focuses on transformational, transactional, and contingency leadership theories and how these styles relate to small businesses in general (Franco \& Matos, 2015; Vidal, Campdesuñer, Rodríguez, \& Vivar, 2017). These conceptual frameworks of effective leadership styles and theories are related mostly to change and improvements (Alqatawenah, 2018). The major concepts studied effective leadership styles include the ability to be transparent, trusting, humble, creative, confident, and with good decision-making, problem solving, and conflict resolution (Yukl, 2012). 


\section{INTERNATIONAL JOURNAL OF ENTREPRENEURIAL KNOWLEDGE}

Issue 2, volume 8, ISSN 2336-2960 (Online)

www.ijek.org

The positive deviance (PD approach) is used to analyze behavioral processes and change among successful individuals to find better solutions. The PD approach seeks certain individuals who have the same challenges, resources, and constraints as others in their group or community, yet who continue to succeed and thrive despite odds not being in their favor. The PD approach is used to explore behavioral processes that help people overcome challenges, find innovative solutions, and use sometimes uncommon strategies and techniques to reach goals and objectives of bettering individuals, groups, or society. The PD approach is used to identify positively deviant leaders who have succeeded in online small business against the $90 \%$ failure odds, and this approach was used in this study as a means of forming interview questions for online small business leaders. Questions surrounding exploration of successful behaviors, strategies, and techniques of online small business leaders probed how they are successful, how they overcome barriers and challenges, what specific steps they take to accomplish goals and objectives, and if they are aware of others using their successful strategies (Heringon \& van de Fliert, 2018; LeMahieu, Nordstrum, \& Gale, 2017; Sternin, 2017).

\subsection{AIM AND METHODOLOGY}

The purpose of this exploratory case study was to explore the perceptions of successful online small business leaders' processes of salient leadership qualities contributing to their positive achievements and accomplishments. Using the positive deviance approach, the study explored the successful strategies and leadership qualities of those succeeding in their online small business against $90 \%$ odds of failure (Forbes, 2015; Fortune, 2014). Through semi-structured interviews, the study investigated details and descriptions of effective leadership qualities.

The following research questions (RQ) guided the study:

RQ: What are some of the most efficient and effective leadership qualities contributing to successful online small businesses?

The following three research sub-questions (SQ) narrowed the focus and provided the foundation for interview questions to fully understand participants' processes and techniques as online small business leaders:

SQ1: How do online small business leaders develop and implement successful leadership qualities that contribute to producing positive organizational outcomes?

SQ2: How do online small business leaders develop and implement successful online leadership contributions to influencing positive techniques, practices, and system processes?

SQ3: How do small online business leaders' practices, such as external entities and relationships, influence effective leadership and leadership practices?

The purpose of this exploratory case study was to explore the perceptions of successful online small business leaders regarding processes of salient leadership qualities contributing to their positive achievements and accomplishments. The study sought to explore and identify some of the salient leadership qualities that contribute to small online business leaders' positive achievements and accomplishments. The study used semi structured, face-to-face interviews with audio recordings, observations, and a review of the online small business literature to explore leadership qualities that could contribute to online small business leaders' success. 


\section{INTERNATIONAL JOURNAL OF ENTREPRENEURIAL KNOWLEDGE}

Issue 2, volume 8, ISSN 2336-2960 (Online)

www.ijek.org

There are 27.9 million small businesses in the United States consisting of 500 or fewer employees, $40 \%$ of which are online small businesses (Small Business Association, 2016). This study included 10 online small business participants who were currently known through community groups. The others in the sample were chosen by snowball techniques or word of mouth through the known participants' social networks.

Because $90 \%$ of online small businesses fail in the first year, the participants were leaders in their online small businesses for more than 1 year, deeming them successful (Bureau of Labor Statistics, 2015). The participants, although working in global online small businesses, were all in Southern California for convenience of access. Demographic information of the participants was collected to identify age, gender, race, marital status, type of business, and number of years the leader had been with the online organization and an online small business leader in general.

Ten participants responded, with one from the 30 online small business website directories solicited and the other nine by the application of snowball sampling and word of mouth from local business friends. The online small business leader participants varied in experiences, tenure at their business and positions, and demographics such as gender, race, age, marital status, religion, and culture. Among the 10 respondents, four were female and six were male. None of the respondents ran the same type of online business; however, some of their responsibilities and routine procedures, such as marketing and social relationships, were similar due to the nature of being online small business owners and leaders.

In terms of race and culture, all the participants were U.S. born. Five were Caucasian; two were African American; two were Latino/a; and one was South Korean. Ages varied from 28 to 62. Five were married, two were single, and three were divorced. Experience in their career fields ranged from 1 year to 15 years. Years as online small business leaders ranged from 1 year to 19 years. The highest number of total employees reached 30.

The interview questions, as the tool for collecting primary data, focused on online small business leaders and their effective and successful processes and qualities. The open, semi structured interviews were audio recorded, transcribed, and data coded. The interviews took 1 to 2 hours to complete. Chunking techniques, mind maps, and notes of major themes during and after interviews were used. Using the qualitative data software Nvivo12, a common word search was ran in order of word frequency, from most to least uses by the participants to identify themes and patterns. Passion and instrinsic motivation was mentioned 25 times. Heightened awareness of time was mentioned 24 times. Face-to-face interaction was mentioned 20 times. Historical person of influence was mentioned 17 times. Adaptability to change was mentioned 16 times. And, problem solving and decision making was mentioned 14 times.879

\subsection{RESULTS}

The RQ in this study was "What are some of the most efficient and effective leadership qualities contributing to successful online small businesses?" The six themes represent the most efficient and effective leadership qualities contributing to successful online small businesses discovered during data analysis. The six themed qualities were passion and intrinsic motivation, heightened awareness of time and time management, importance of face-to-face interactions, historical person of influence, adaptability to change, and problem solving and decision making.

\section{Theme 1: Passion and Intrinsic Motivation}

The first theme that emerged from the data analysis was being passionate and enjoying their positions and career fields, which spurred their intrinsic motivation. Passion and intrinsic motivation allowed 


\section{INTERNATIONAL JOURNAL OF ENTREPRENEURIAL KNOWLEDGE}

Issue 2, volume 8, ISSN 2336-2960 (Online)

www.ijek.org

participant leaders to overcome obstacles, remain perseverant, be committed to achieving goals, be fully engaged, and be helpful and inspiring to others. All 10 participants stressed their contentment and overall happiness with their chosen work.

\section{Theme 2: Heightened Awareness of Time and Time Management}

The second theme involved all participants mentioning a heightened awareness of time in some form, such as time management or time schedules. Four participants discussed procrastination regarding undesirable activities, such as a difficult conversation with an employee, invoices and paperwork, and end-of-day errands. Six participants expressed heightened awareness of the importance of areas, such as task completion for clients and turnaround time, maintaining scheduled family, work, and self-care balanced time, time for spiritual and physical fitness, social time with others for work, and making time for community groups and social media activities. Five participants mentioned being conscious about how time spent at work needed to be fast and efficient to complete tasks for customer satisfaction. Not all participants were pleased about the required time to complete some tasks as online small business leaders, such as procrastinating to avoid employee's negative reaction or losing track of time building face-to-face relationships. Good understanding of time management also allowed delegating and outsourcing work duties.

\section{Theme 3: Importance of Face-to-Face Interactions}

The third theme that emerged among the online small business leaders was the importance of oldfashioned social connections, face-to-face conversations, and in-person social networking. Eight of 10 participants mentioned how face-to-face interactions and referrals from others far exceeded their personal efforts and assisted with avoidance of large marketing costs. Seven of 10 believed face-to-face interactions with clients; external others such as court clerks, suppliers, other contractors, attendees at conferences and community network groups; and others in similar online businesses assisted in building more personable relationships and enhanced performance outcomes through these closer relationships. Seven participants mentioned how building outside personal relationships with clients in face-to-face interactions was beneficial and increased their success by promoting business, developing more online business knowledge, and creating more word-of-mouth marketing referrals.

\section{Theme 4: Historical Person of Influence}

The fourth theme emerging from the data was the participants' historical means of someone with positive encouragement influencing them to become better in some regard. The individual of great influence in their past provided the online small business leader with confidence and a motivational boost to some extent, and some participants felt an obligation to reciprocate the act of generosity and kindness to others through their online small business missions and future goals. The participants were very self-aware, humbled, and possessed integrity in giving back to others and raising others to be better people and fulfill roles that assisted society. The online small business leaders who participated in the study, even though not directly prompted or asked purposely, wanted to reveal someone from their past who contributed to their successes.

\section{Theme 5: Adaptability to Change}

Another theme derived from the participant interviews involved adaptability to change. All the online small business leaders understood that change was inevitable and the extreme importance of adapting quickly, taking action swiftly, or forward thinking regarding change to remain competitive and retain customers. Four participants have to keep advancing in technology to remain competitive in conducting their online small business for profit and to retain and obtain clients; although only two expressed change 


\section{INTERNATIONAL JOURNAL OF ENTREPRENEURIAL KNOWLEDGE}

Issue 2, volume 8, ISSN 2336-2960 (Online)

www.ijek.org

in a positive way. All participants were aware and acknowledged they have either mastered or adapted to change better than their internal and external engaging relations related to their online small business. All participants also mentioned having increased their adaptability to change over time with their online small business, their field interests, or their external relations in some form.

\subsection{DISCUSSION}

Multiple leadership qualities and themes of successful online small business leaders emerged in the findings. The analysis of the data findings was conducted in response to the research questions to consider how online small business leaders develop, perform, and operate traits, contributions, positive environmental factors, and external relationships to contribute to successful positive outcomes. The study resulted in new results and findings filling the gap in literature regarding online small business leaders' effectiveness for success and these six themed qualities.

After interviewing 10 participants regarding their experiences, perspectives, and practice techniques, six major themes emerged from the analysis of the online small business leaders: passion and intrinsic motivation, heightened awareness of time and time management, importance of face-to-face interactions, historical person of influence, adaptability to change, and problem solving and decision making. Although these six themes are not new to leadership or leadership theory in general, these six combined qualities from successful online small business leaders are new to the body of literature.

\section{Theme 1: Passion and Intrinsic Motivation}

The most significant theme emerging from the analysis of the interview responses of participants in this exploratory case study regarding effective leadership qualities in online small businesses was passion and intrinsic motivation. All 10 participants mentioned passion and motivation. The online small business leaders, through their intrinsic motivation, desired to continually achieve successful outcomes and positive external relations. In addition to intrinsic motivation, participants used the word "passion" regarding their work. Singh (2017) found that passion and intrinsic motivation related to work led to higher leader and employee productivity and positive business transactions. This significant theme of passion and motivation that emerged from this study as important qualities for work practices in successful online small businesses aligns well with Singh's (2017) findings.

Intrinsic motivation is the internal drive highly related to certain held beliefs and values of individuals that leads to greater commitment, creativity, productivity, innovation, and ability to maintain focus on goals and objectives, resulting in higher self-esteem, a positive outlook, and personal satisfaction (Cetin \& Asşkun, 2018). Singh's (2017) research on manager's motivation and students in organizations demonstrated intrinsic factors, with tapping into emotions of workers playing a larger role in motivation by creating a culture of respect, trust, autonomy, and recognition. A study by Gilbert and Kelloway (2018) regarding managers and employees showed the more intrinsically motivated the leader, the more motivated and reported higher work satisfaction of employees. Passion in relation to leadership, closely related to the intrinsic motivation definition, entails positive and deep reasoning, which results in inspiration, excitement, and enthusiasm to make positive contributions to the development, performance, and operations of online small businesses (Murnieks et al., 2016). Afsar, Badir, and Kaini's (2016) study findings showed passion as a pro-environmental productive behavior in organizations. DeClerco and Belausteguigoitia (2016) discovered that passion, in addition to tenacity, creates resilience to conflict and raises job satisfaction. The use of the word "passion" in addition to factors of intrinsic motivation demonstrates positive benefits of conflict resolution and productive behaviors for leaders in businesses. "Passion" and "driven" qualities lead to focus and vision in forward thinking, motivating and inspiring others with energy and enthusiasm, and having a heightened positivity and deep joy about work. 


\section{INTERNATIONAL JOURNAL OF ENTREPRENEURIAL KNOWLEDGE}

Issue 2, volume 8, ISSN 2336-2960 (Online)

www.ijek.org

In terms of leadership qualities, having a driven attitude also leads to better problem solving, decision making, creativity and innovation, teamwork, eternal relationships, and social networking. The ability to lead and stimulate others to action is also directly related to passion and intrinsic motivation (Northouse, 2018).

In contrast, extrinsic motivation was found by Wisanupong and Ford (2016) and Dunne, Williams, McDowell, and Geho (2016) to be less motivating and resulting in less creativity and innovation. Intrinsic motivation is in contrast to extrinsic motivation, in which an individual completes tasks and expectations to earn money, rewards, fame, praise, or avoidance of negative outcomes. Extrinsic motivation, in comparison to intrinsic motivation, usually results in lower motivation and inability to maintain high performance or focus to achieve completion of goals or objectives (Bande et al., 2016).

To the online small business leaders, passion and intrinsic motivation enhanced their ability to create, maintain, and operate productive and positive environmental factors. The study's findings support the positive reasoning and high morale and productivity of these online small business leaders. In addition to intrinsic motivation, the online small business leaders mentioned being more satisfied overall by following their passion to their career field.

\section{Theme 2: Heightened Awareness of Time and Time Management}

Online small business leaders who participated in this study had a heightened awareness of time, with some using time structures extremely well and others readily admitting they procrastinated about certain tasks perceived negative. The online small business leaders discussed the importance of time and time management as a big part of their daily performance, development, and operations, and they reflected on the importance of how they desired to change their time management or would be changing their time management goals in the future. The participants' responses reflected the importance of leaders enabling others to guide their own decisions or allowing others' input in making online small business decisions. Also, the participants mentioned time management and prioritizing others in current and immediate situations over other responsibilities.

To have the ability to handle multiple tasks effectively and efficiently like many of the participants, leaders need awareness of time management (Naidoo et al., 2014). Time management is important for handling multiple tasks and responsibilities as a leader and knowing wisely when to delegate (Naidoo et al., 2014). Time is also important to understand the future goals and business plan of online small businesses. Time management is essential for developing strategies for personal and organization goals and finding which qualities and patterns, timesaving strategies, and work-life balance are most effective, because time is a commodity (Farrell, 2017). In regard to leadership and the online small business leader, timing consciousness as an attribute leads to motivational factors and success (Choi, Kihwan, \& Kang, 2017). A heightened awareness of time and time management enhances success for goals, identifying strategies, and creating good work-life balance.

In contrast, heightened awareness of time and multitasking both lead to stress and anxiety and results in a lack of flexibility and change (Ryden \& El Sawy, 2019). If timing and tasks are pre-set for the day, emergencies and new incoming information can create vague or confusing priorities. Multitasking, related to time management, also leads to less cognitive functioning and less work-related clarity (Ophir, Nass, \& Wagner, 2009). Even though some external research shows heightened time management and multitasking lead to stress and lack of flexibility, these were not problems found among or stated by the participants in this study.

Although perspectives varied on the awareness and use of time, participants were conscious of how their time was used and importance of prioritizing tasks to achieve the best use of time. By setting priorities, 


\section{INTERNATIONAL JOURNAL OF ENTREPRENEURIAL KNOWLEDGE}

Issue 2, volume 8, ISSN 2336-2960 (Online)

www.ijek.org

whether related to emergencies, positive relations, or procrastination to avoid bad feelings, the online small business leaders demonstrated consciousness of time. In addition to the other themes found in this study, this focus on time is a factor in online small business leaders' success, especially because it leads to the ability to be goal oriented and results driven (Farrell, 2017).

\section{Theme 3: Importance of Face-to-Face Interactions}

The online small business leaders in this study also recognized the importance of face-to-face interactions in addition to their online business interactions. These face-to-face interactions were important to the participants for their personal satisfaction, marketing and referrals, and promotion of their online small businesses. Even though five participants mentioned not being very outgoing individuals and preferring to avoid being center of attention, they still valued and understood the importance of face-to-face communication in relation to their online small business success.

Face-to-face interactions add a positive contributing factor that assists in marketing and building a stronger consumer foundation (Alnsour, 2018). Face-to-face social networking relationships assist in accomplishing goals and objectives more efficiently and adding to individual growth and opportunity (Hickman, 2016; Plouffe et al., 2016). Face-to-face interactions in supporting and advocating for community groups add to positive external relationships (Arruda \& Levrini, 2005). Leaders who contribute to social agenda groups in a positive way also have more satisfied employees (Arruda \& Levrini, 2005). The participants in this study found face-to-face interactions beneficial for enhanced learning, marketing, and increasing their presence and support in their philanthropic social groups.

In contrast, leaders who exploit cultures through negative practices have less social support, external relations, employee motivation, and profit, which was not the case with the study's online small business leaders (Arruda \& Levrini, 2015). Face-to-face social networking could work against an online small business leader if their popularity, branding, or beliefs become a negative target (Alnsour, 2018). Also, if face-to-face connections are not nourished and relatable, it could lead to disappointment or a feeling of isolation (Andrews, 2017). These negative face-to-face interactions were not a problem mentioned by the participants, because their experiences involved positive face-to-face interactions with healthy networking, branding, and social connections.

The online small business leadership quality of face-to-face and word-of-mouth interactions, relationships, and referrals contributed to a more participative leadership, such as allowing others to assist in decision making and ensuring the clients, employees, and external relationships contributed input to enhance the online small business leaders' directional choices for their online small business success (Cappa et al., 2016). Also, external relationships contribute immensely to increased marketing and outside referrals for online small businesses (Alnsour, 2018). By spending less time and money on marketing, the online small business leaders had more financial freedom and time to spend, reinvest, and disperse monetary extras elsewhere in their online small business and reserve extra time for other company endeavors. So, branding of self and being charismatic as an extrovert for marketing were not important qualities for success (Cappa et al., 2016).

\section{Theme 4: Historical Person of Influence}

The qualities of humility and passing along kindness to others based on a historical person of influence was shown by the participants. Two participants wanted to transform women's status in society and desired to transform the future of their particular groups of focus. Three other participants stated they desired to assist others through definitive goals for their businesses and even wrote the goals and objectives in their mission statements. These participants' online small business goals were designed to assist less-fortunate individuals. 


\section{INTERNATIONAL JOURNAL OF ENTREPRENEURIAL KNOWLEDGE}

Issue 2, volume 8, ISSN 2336-2960 (Online)

www.ijek.org

Mentorship and a historical person of influence have been shown to enhance leadership and success (Sihi \& Lawson, 2016). By learning from willing experienced others, an online small business leader is more likely to be successful by learning from a historical person of influence the basic tools, skills, processes, and network for success (Nandedkar \& Brown, 2018). A historical person of influence provides positive feedback, advice, and raises a person's self-confidence through encouragement or modeling (Jenson, 2019; Thomas, 2019). Having a positive historical person of influence allows for trust and openness to ask questions and vent problems with better resolution, solutions, and decision making. Due to the mentor-mentee relationship or positive encouragement from someone in their life, online small business leaders are more likely to build teamwork and collaborative relationships and work to assist others in being successful for their own benefits and future. A historical person of influence allows for different views and perspectives outside the online small business leaders, which creates and influences better innovation and creativity to problem solve (Cumberland et al., 2016; Smith, 2018). The online small business leaders mentioned the historical person of influence having a positive and helpful role in their careers, and the participants desired to reciprocate by giving back to the community or assisting others because of this positive, influential person of their past.

In contrast, a historical person of influence could be a negative effect in certain aspects of life, leading to discouragement of an online small business leader (Fellnhofer \& Mueller, 2018). Historical persons of influence may result in online small business leaders' negative reactions if they don't meet the expectations of the historical person of influence or their role modeled successes at the same rate. The pressure to stay in certain areas recommended by the historical person of influence or taking outdated advice regarding online small business from the historical person of influence could lead to less success or burnout. The historical person of influence may encourage an online small business leader to try certain business objectives, products, services, and processes that lead to stress or frustration rather than success (Chen, Ding, \& Li, 2016; Fellnhofer \& Mueller, 2018). The participants did not mention the historical person of influence having a negative effect in their current positions or their business choices and actions, but rather having lasting, positive effects on their current success status.

Historical persons of influence who were already successful in business can demonstrate to online small business leaders' strategies and methods to improve their work, skills, and network (Nowiński \& Haddoud, 2019). The participants in this study cherished the positive influences and effects of their historical person of influence. The online small business leaders in the study also wanted to be persons of influence and pass on their experience to others in the future in a positive way.

\section{Theme 5: Adaptability to Change}

Adaptability to change was another leadership quality that participants were knowledgeable of, and they understood the importance of futuristic thinking to acclimate to change. The online small business leaders admitted needing to adapt to change and recognized the importance of practicing, achieving, bettering, and preparing their personal selves and their online small businesses for change. Change was not a factor related to their years of experience as an online small business leader, but rather related to their ability to learn, accept, and adapt to change for online small business success. Although some of the participants embraced change with an optimistic and encouraging outlook and proactive stance, some were not as positive in their responses when discussing the matters of change but understood and adapted to change anyway.

Change-oriented leadership characteristics are related to positive organizational outcomes (Abdulla et al., 2017). Adapting to change efficiently and effectively in processes, performance, and operations allows an organization to be more productive and more competitive in making new contributions to its field. Leaders are more successful if they are fluid in responding to problems and foreseeing change (Northouse, 2018). Recognizing the evolution of processes, systems, and services and the complex 


\section{INTERNATIONAL JOURNAL OF ENTREPRENEURIAL KNOWLEDGE}

Issue 2, volume 8, ISSN 2336-2960 (Online)

www.ijek.org

identities involved to orchestrate the best plan and appointing change agents to assist with those current and future fluctuations adds to success (Northouse, 2018). Being flexible and positive during times of change assists in internal and external relationships being more adaptive, positive, and productive with less negativity, stagnation, or conflict (Gjerde, 2018; Vidal et al., 2017). The participants, in addition to possessing the other five themes, were extremely adaptable to change, which contributed to their success beyond their peers.

In contrast, adapting to change may result in negative reactions and results. Adapting to change too quickly may result in employee stress, resistance, confusion, and lack of coping (Gjerde, 2018). Adapting to change may also result in consumer and profit loss from disruption in products and services and changes in customer loyalty (Gabriela, 2018). Sometimes change is risky, and the decisions implemented are not always beneficial, nor do they always result in positive outcomes. When online small business leaders are unable to find new patterns and trends in change, the results may not be favorable loyalty (Sandulescu \& Cristina, 2018). The participants mentioned how some decisions and actions were not enjoyable; however, their risk taking and adaptability to change had positive outcomes for their online small businesses' success.

Change is necessary, constant, and unavoidable, and the online small business leaders expressed their knowledge of the demands of change. Although some respondents were not pleased about change transformations, they understood and adapted to change. Some participants were proactive and futuristic thinkers by adapting to change - trying to find patterns and the next product or services needed to remain ahead of the competition and please customers.

\section{Theme 6: Problem Solving and Decision Making}

The last theme related to the online small business leaders' successful leadership qualities were their ability to make wise decisions and problem solve effectively and efficiently. The participants were transparent in acknowledging they didn't always having the solutions to obtain the best outcomes; however, they were humble enough to ask others for support and find the best actions. These decision-making and problem-solving skills assisted in their positive environmental factors, ability to change, and the ability to make swift contributions. Online small business leaders with high problem-solving and decision-making skills were better negotiators to handle real-life problems and real-life employee and consumer problems. The online small business leaders demonstrated these qualities, contributing to their success.

Effective problem solving and efficient decision making are part of positive leadership for success (Northouse, 2018). Problem solving is pertinent for achievement in daily tasks and to accomplish goals and business objectives (Figueroa et al., 2011). Problem solving and effective decision-making helps improve products and make operational enhancements (Figueroa et al., 2011). Problem solvers and good decision makers also are more innovative and creative in maximizing business performance (Avci et al., 2017; Khan et al., 2017). The participants could concurrently analyze their past, present, and future in their overall statements and possessed the six themed qualities, resulting in the ability to creatively, innovatively, and intuitively determine the best decisions and actions for their successful online small businesses.

In contrast, negative consequences occur without effective and efficient problem solving and decision making (Matsudaira, 2019). Indecisiveness or the inability to act fast with problem solving and decision making could lead to loss of profit and consumers, loss of reputation and respectability, and loss of employees and outside relations (Matsudaira, 2019). By being hesitant in problem solving and decision making, the problems of businesses build and create worse problems. Leaders who are ineffective in their problem solving and decisions are often seen as lazy, selfish, incompetent, inexperienced, and careless (Bucurean, 2018). Although some risk taking in decisions relates to overall positive outcomes, making 


\section{INTERNATIONAL JOURNAL OF ENTREPRENEURIAL KNOWLEDGE}

Issue 2, volume 8, ISSN 2336-2960 (Online)

www.ijek.org

poor decisions usually results in negative outcomes (Antoncic, et al., 2018). The participants who noted poor decision making or problem solving also mentioned each instance as a learning experience and made improvements that contributed to their online small business success.

Overall, online small business leaders were proactive in problem solving and decision making, because they understood the importance of wisdom and follow through in these problem solving and decisionmaking qualities. The online small business leaders, when not knowledgeable or skilled enough to problem solve or make decisions for their online small businesses, asked for help and sought information from experts. By being humble and transparent, the online small business leaders gained confidence in problem solving and decision making through improvement in performance and products. The online small business leaders in this study were decision makers and problem solvers in their fields and in circumstances in their control and power.

\subsection{CONCLUSION}

The general problem was online small business leaders face challenges separate and unique from traditional ground business leaders and big e-commerce business leaders who are turning ground businesses to online global businesses (Lowell, 2016; Lupasc \& Gheorghe, 2016). The specific problem was that online small business leaders lack effective leadership skills and actions to address the unique challenges of online small businesses, resulting in a 90\% first-year failure rate (Bureau of Labor Statistics, 2015; Raghupathi \& Fogel, 2015). The six quality themes of the online small business leaders in this study included possessing the passion and internal motivation, a heightened awareness of time and time management, an understanding of the importance of face-to-face interactions for social networking, a historical person of influence, adaptability to change, and fast and effective decision-making and problem-solving abilities. By understanding these new research outcomes of successful online small business leader qualities, those seeking betterment in their industries may increase and promote these characteristics to improve their online small businesses and raise future success rates.

\section{REFERENCES}

Afsar, B., Badir, Y., \& Kaini, S. (2016). Linking spiritual leadership and employee pro-environmental behavior: The influence of workplace spirituality, intrinsic motivation, and environmental passion. Journal of Environmental Psychology, 45(1), 79-88. doi:10.1016/j.jenvp.2015.11.011

Alnsour, M. (2018). Online relationship marketing for banks in face-to-face economies. Journal of Marketing Analytics, 6(3), 105- 116. doi:10.1057/s41270-018-0032-z

Alqatawenah, A. (2018). Transformational leadership style and its relationship with change management. Business: Theory and Practice, 19(1), 17-24. doi:10.3846/btp.2018.03

Andrews, D. (2017). A space for place in business communication research. International Journal of Business Communication, 54(3), 325-336. doi:10.1177/2329488416675842

Arruda, M., \& Levrini, G. (2015). Successful business leaders' focus on gender and poverty alleviation: The Lojas Renner case of job and income generation for Brazilian women. Journal of Business Ethics, 132(3), 627-638. doi:10.1007/s10551-014-2356-8

Avci K., Çınaroğlu, S., \& Top, M. (2017). Perceptions of pediatric nurses on ethical decision making processes. Systemic Practice and Action Research, 30(1), 67-84. doi:10.1007/s11213-016-9386-3

Bande B., Fernández-Ferrín, P., Varela-Neira, C., \& Otero-Neira, C. (2016). Exploring the relationship among servant leadership, intrinsic motivation and performance in an industrial sales setting. Journal of Business \& Industrial Marketing, 31(2), 219-231. doi:10.1108/JBIM-03-2014-0046 


\section{INTERNATIONAL JOURNAL OF ENTREPRENEURIAL KNOWLEDGE}

Issue 2, volume 8, ISSN 2336-2960 (Online)

www.ijek.org

Bucurean, M. (2018). The effects of moods and emotions on decision making process: A qualitative study. Annals of the University of Oradea, Economic Science Series, 1(1), 423-429. Retrieved from http://ideas.repc.org/a/ora/journl/vly20181lp423-429.html

Bureau of Labor Statistics (2015). Entrepreneurship and the U.S. economy. Retrieved from https://www.bls.gov/bdm/entrepreneurship/entrepreneurship.htm

Cappa, F., Laut, J., Oded, N., Giustiniano, L., \& Porfini, M. (2016). Activating social strategies: face-toface interaction in technology-mediated citizen science. Journal of Environmental Management, 182(1), 374-384. doi:10.1016/j.jenvman.2016.07.092

Cetin, F., \& Aşkun, D. (2018). The effect of occupational self-efficacy on work performance through intrinsic work motivation. Management Research Review, 41(2), 186-201. doi:10.1108/MRR-03-20170062

Chen, N., Ding, G., \& Li, W. (2016). Do negative role models increase entrepreneurial intentions? The moderating role of self-esteem. Basic and Applied Social Psychology, 38(6), 337-350. doi:10.1080/01973533.2016.1217223

Choi, S., Kihwan, K., \& Kang, S. (2017). Effects of transformational and shared leadership styles on employees' perception of team effectiveness. Social Behavior and Personality, 45(3), 377-386. doi:10.2224/sbp.5805

Cohen-Almagor, R. (2011). Internet history. International Journal of Technoethics, 2(2), 45-64. doi:10.4018/jte.2011040104

Cope, O., \& Waddell, D. (2001). An audit of leadership styles in e-commerce. Managerial Auditing Journal, 16(9), 523-529. doi:10.1108/02686900110406638

Creswell, J., \& Creswell, D. (2017). Research design: Qualitative, quantitative, and mixed methods approach. Thousand Oaks, CA: Sage.

Cumberland, M., Herd, A., Alagaraja, M., \& Kerrick, A. (2016). Assessment and development of global leadership competencies in the workplace: A review of literature. Advances in Developing Human Resources, 18(3), 301-317. doi:10.1177/1523422316645883

DeClerco, D., \& Belausteguigoitia, I. (2016). Overcoming the dark side of task conflict: Buffering roles of transformational leadership, tenacity and passion for work. European Management Journal, 35(1), 78-90. doi:10.1016/j.emj.2016.06.008

Dey, R., D’Souza, R., \& D’Souza, J. (2015). Relationship between brick and mortar stores and mcommerce facilitates customers towards shopping online. Educational Quest, 6(3), 189-196. doi:10.5958/22307311.2016.00006.4

Doody, O., \& Doody, C. (2015). Conducting a pilot study: Case study of a novice researcher. British Journal of Nursing, 24(21), 1074-1078. doi:10.12968/bjon.2015.24.21.1074

Dunne, T., Williams, A., McDowell, D., \& Geho, P. (2016). The impact of leadership on small business innovativeness. Journal of Business Research, 69(11), 4876-4881. doi:10.1016/j.jbusres.2016.04.046

Farrell, M. (2017). Time management, Journal of Library Administration, 57(2), 215-222. doi:10.1080/01930826.2017.1281666

Figueroa, P., Savage R., Romero, R., \& Luechtefeld, R. (2011). A qualitative analysis for the facilitation of problem completion amongst dyads of engineering students. Paper presented at the 2011 Frontiers in Education Conference, Rapid City, SD. doi:10.1109/FIE.2011.6142867

Forbes (2015). Why start-ups will fail. Retrieved from https://www.forbes.com/sites/neilpatel/2015/01/16/90-of-startups-will -fail-heres-what-you-need-to-know-about-the-10/?sh=77b77eff6679

Fortune (2014). Why start-ups fail according to their founders. Retrieved from https://fortune.com/2014/09/25/why-startups-fail-according-to-their-founders/

Franco, M., \& Matos, P. (2015). Leadership styles in SMEs: A mixed-method approach, International Entrepreneurship and Management Journal, 11(2), 425-451. doi:10.1007/s11365-013-0283-2

Friedman, M. (2014). How high can online go: Experts see web sales leveling off after quick growth. Arkansas Business, 31(9), 1. 


\section{INTERNATIONAL JOURNAL OF ENTREPRENEURIAL KNOWLEDGE}

Issue 2, volume 8, ISSN 2336-2960 (Online)

www.ijek.org

Gabriela, C (2018). The necessity and importance of money in time. Economic Sciences Series, 33(1). Retrieved from http://stec.univ-ovidius.ro/html/anale/RO/wp-content/uploads/2018/08/261.pdf

Gilbert, S., \& Kelloway, K. (2018). Self-determination leader motivation and follower perceptions of leadership. Leadership and Organization Development Journal, 39(5), 608-619. doi:10.1108/LODJ-092017-0262

Gjerde, R. (2018). 5 strategies for retaining talent during change. Journal of Property Management, 83(1), 68.

Gross, R. (2016). Towards an understanding of the relationship between leadership styles and strategic thinking: A small and medium enterprise perspective. Journal of Business Studies Quarterly, 8(2), 22$39 . \quad$ Retrieved

from https://search.proquest.com/openview/8b5c9a812524a96df7431c85288a5d33

Hoch, J., Bommer, W., Dulebohn, J., \& Wu, D. (2018). Do ethical, authentic, and servant leadership explain variance above and beyond transformational leadership? A meta-analysis. Journal of Management, 44(2), 50-529. doi:10.1177/0149206316665461

Jenson, B. (2019). Be the mentor you wanted when you were starting out. Physician Leadership Journal, 6(2), 49-50. Retrieved from https://www.physicianleaders.org/news/be-the-mentor-you-wantedwhen-you-were-starting-out

Joseph, C. (2017). Problems with doing business on the internet. Chron. Retrieved from http://smallbusiness.chron.com/problems-doing-business-internet-328.html

Korzynski, P. (2013). Online social networks and leadership: Implications of a new online working environment for leadership. International Journal of Manpower, 34(8), 975-994. doi:10.1108/IJM-072013-0173

LeMahieu, P., Nordstrum, L., \& Gale, D. (2017). Positive deviance: Learning from positive anomalies. Quality Assurance in Education, 25(1), 109-124. doi:10.1108/QAE-12- 2016.0083

Lowell, R. (2016). An application of complexity theory for guiding organizational change. The PsychologistManager Journal, 19(3-4), 148-181. doi:10.1037/mgr0000044

Lupasc, I., \& Gheorghe, G. (2016). SaaS model, virtualization and information safety: Challenge for online business. Risk in Contemporary Economy, 3(1), 104-109. Retrieved from http://www.rce.feaa.ugal.ro/images/stories/RCE2016/LupascGheorghe.pdf

Mackinnon, S., \& Pinette, J. (2016). Considerations and benefits of implementing an online database tool for business continuity. Journal of Business Continuity and Emergency Planning, 9(3), 272-280. Retrieved from

https://www.ingentaconnect.com/content/hsp/jbcep/2016/00000009/00000003/art00008

Matsudaira, K. (2019). Design patterns for managing up. Communications of the ACM, 62(3), 43-45. doi:10/1145/3303878

Murnieks, C., Cardon, R., Sudek, D., White, W., \& Brooke, T. (2016). Drawn to the fire: The role of passion, tenacity, and inspirational leadership in angel investing. Journal of Business Venturing, 31(4), 468-484. doi:10.1016/j.jbusvent.2016.05.002

Naidoo, R., Gosling, J., Bolden R., O’Brien, A., \& Hawkins, B. (2014). Leadership and branding in business schools: A Bourdieusian analysis. Higher Education Research \& Development, 33(1), 126-138. doi:10.1080/07294360.2013.864612

Nandedkar, A., \& Brown, R. (2018). Transformational leadership and positive work outcomes. International Journal of Organization Theory and Behavior, 21(4), 315-327. doi:10.1108/IJOTB-09-20180105

$\mathrm{Ng}, \mathrm{H} .$, \& Kee, D. (2018). The core competence of successful owner-managed SMEs. Management Decision, 56(1), 252-272. doi:10.1108/MD-12-2016-0877

Northouse, P. (2018). Leadership: Theory and practice. Thousand Oaks, CA: Sage.

Nowiński, W., \& Haddoud, M. (2019). The role of inspiring role models in enhancing entrepreneurial intention. Journal of Business Research, 96(1), 183-193. doi:10.1016/j.jbusres.2018.11.005 


\section{INTERNATIONAL JOURNAL OF ENTREPRENEURIAL KNOWLEDGE}

Issue 2, volume 8, ISSN 2336-2960 (Online)

www.ijek.org

Ophir, E., Nass, C., \& Wagner, A. (2009). Cognitive control in media multitaskers. Proceedings of the National Academy of Sciences of the Unites States of America, 106(37), 15583-15587. doi:10.1073/pnas.0903620106

Plouffe, C., Bolander, W., Cote, J., \& Hochstein, B. (2016). Does the customer matter most? Exploring strategic frontline employees' influence of customers, the internal business team, and external business partners. Journal of Marketing, 80(1), 106-123. doi:10.1509/jm.14.0192

Ryden, P., \& El Sawy, O. (2019). How managers perceive real-time management: Thinking fast and flow. California Management Review, 61(2), 155-177. doi:10.1177/00081256188118840

Sihi, D., \& Lawson, K. (2016). Marketing leaders and social media: Blending personal and professional identities. Journal of Marketing Theory \& Practice, 26(1/2), 38-54. doi:10.1080/10696679.2017.1389240.

Silzer, R., Church, A., Rotolo, C., \& Scott, J. (2016). I-O practice in action: Solving the leadership potential identification challenge in organizations. Industrial and Organizational Psychology, 9(4), 814830. doi:10.1017/iop. 2016.75

Singh, R. (2017). The impact of intrinsic and extrinsic motivators on employee engagement in information organizations. Journal of Education and information Sciences, 57(2), 197-206. doi:10.3138/jelis, 57.2.197.

Smith, D. (2018). Understanding the behaviors of leaders and team members to improve your organization. Journal of Financial Planning, 31(1), 20-22. Retrieved from https://www.onefpa.org/journal/Pages/JAN18-Understand-the-Behaviors-of- Leaders-andTeam-Members-to-Improve-Your-Organization.aspx

Stern, T., Friedman, L., \& Friedman, H. (2017). How we got here: Connectivity, creativity, confluence and internet culture. Journal of International Technology and Information Management, 26(1), 21-44. Retrieved from https://scholarworks.lib.csusb.edu/jitim/vol26/iss1/3/

Sternin, J. (2017). Positive deviance: A new paradigm for addressing today's problems today. Journal of Corporate Citizenship, 5(1), 57-62. Retrieved from http://www.jstor.org/stable/jcorpciti.5.57

Thomas, E. (2019). Strengthening the leadership platform through effective mentoring programs. Conflict Resolution \& Negotiation Journal, 2019(1), 3-13.

United States Small Business Administration (2019). Small business profile. Retrieved from https://www.sba.gov/sites/default/files/advocacy/United_States.pdf

Verma, V., Sharma, D., \& Sheth, J. (2016). Does relationship marketing matter in online retailing? A meta-analytic approach. Academy of Marketing Science Journal, 44(2), 206-217. doi:10.1007/s11747015-0429-6

Vidal, G., Campdesuñer, R., Rodríguez, A., \& Vivar, R. (2017). Contingency theory to study leadership styles of small businesses owner-managers at Santo Domingo, Ecuador. International Journal of Engineering Business Management, 9(1), 1-11. doi:10.1177/1847979017743172

Wisanupong, P., \& Ford, M. (2017). Does public service motivation always lead to organizational commitment? Examining the moderating roles of intrinsic motivation and ethical leadership. Public Personal Management, 46(3), 211-238. doi:10.1177/0091026017717241

Wolfinbarger, M., \& Gilly, M. (2001). Shopping online for freedom, control, and fun. California Management Review, 43(2), 34-55. doi:10.2307/41166074

Yukl, G. (2012). Leadership in organizations. Boston, MA: Pearson.

\section{BRIEF DESCRIPTION OF AUTHOR:}

\section{Dr. Mandy Smith, Professor and Program Coordinator}

Dr. Mandy Smith holds a B.A. and M.A. in Sociology and a Doctorate of Management in Organizational Leadership from the University of Phoenix. She has been teaching in higher education for 14 years from Associate's to Master's level students, including 12 years at the University of Phoenix. In addition, she has taught and lectured at Riverside Community College, University of California, Riverside, California 
INTERNATIONAL JOURNAL OF ENTREPRENEURIAL KNOWLEDGE

Issue 2, volume 8, ISSN 2336-2960 (Online)

www.ijek.org

Baptist University, and La Sierra University. She has been a social worker in various capacities for five years and is currently the Program Coordinator for the Love Your Neighbor Collaborative (LYNC) through Path of Life. She has served on various committees and boards, including Riverside International Relations Council and RUSD LCAP Advisory Committee, to advocate positive change in her community. 